\title{
The Application of Creative Design in Apparel Industry
}

\author{
Bingqiang Tian, Shouzhong Hu \\ Shanghai University of Engineering Science, Shanghai, China \\ Email: tianbingqiang@126.com
}

Received 28 May 2015; accepted 23 February 2016; published 26 February 2016

Copyright (C) 2016 by authors and Scientific Research Publishing Inc.

This work is licensed under the Creative Commons Attribution International License (CC BY). http://creativecommons.org/licenses/by/4.0/

C) (i) Open Access

\begin{abstract}
The article explained and analyzed the creative design of clothing from concept to the main manifestations and characteristics, and the relationship between apparel feature type and creative design of clothing was discussed. It presented ideas that creative design of clothing reflect in variety of clothing types mainly in three forms: subversion, innovation-based and functional innovation. Creative design of clothing is the fundamental of development of Chinese fashion. It should be done to reform education and train creative design fashion talent.
\end{abstract}

\section{Keywords}

\section{Creative Design of Clothing, Originality, Style of Expression}

\section{Introduction}

The era of the creative economy is coming, creative has become the core competitiveness of individuals and organizations. Experienced the economic crisis sweeping the globe and the rational thinking of China's sustainable development after great development, it is increasingly clear that changing "Made in China" to "create in China" is the inevitable direction of future development of China and the only way for the great rejuvenation of Chinese nation. "Creative design" and "technological innovation" are the two strong boost chariot wheels of transition forward. For the field of fashion design is concerned and belongs to the scope of creative industries fashion, it is assumed at place in advance. Focusing on the implementation of brand strategy, strengthening creative costume design, and nurturing creative talent in fashion are the keys to achieve restructuring development lies.

\section{The Awareness about Concepts Related to Creative Design of Clothing}

\subsection{Creativity}

There are variety understandings of the creativity. Summarizing multiple interpretations, we can draw such a 
definition: creativity is the creative idea, it is not a repetition of some safe choices, but innovation, with original features; the same time, creative is suitable for the restrictions given by the target with enforceable features.

\subsection{Creative Design}

Creative ideas will be adopted to a certain performance and implementation through some creative activities. Literally can be understood as the design of the ideas, meaning, means with creative characteristics. From the perspective of modern design, the creative design can be understood as all the designs which really break more or less something already exists. Creative design is included in the scope of innovative design, but its directivity is more specific, more focus is expression of the creative ideas and means for the design, and it injects the design with the soul and vitality.

\subsection{Creative Design of Clothing}

Creative Design of Clothing is creative design with clothing as the carrier. It is also be interpreted as the clothing design with creative ideas, means, and it often creates a desirable new lifestyle through the way of "storytelling", this touches the hearts of apparel consumers, causing their the desire to have. The terms like "Story" and "experience design" and so on are sufficient to prove that "means" has become a valuable commodity assets attached.

As speaking creative design of clothing, it is easy for people to think of those fashion designs with visual impact, original art feeling and strong performance, and not those of the more life, people usually wear clothes. Having this idea is justified, because the "original" is indeed a measure standard of the characteristics of creative design. The artistic fashion design is easy to understand the feeling of creativity, but the creative concept is broad and non- high and low, both as reflected in the performance art clothing design and practical clothing design, but the difference exists in fashion design originality on the extent and manifestations.

\section{Clothing type and Creative Design}

According to the differences of consumer objects, wearing occasions, taking functions and so on, clothing is divided into many types. In addition to the division of basic clothing categories, etc. it can be classified as art performance clothing and practical clothing, accordance with the artistic and practical features; and haute couture, prét-à-couture and prét-à-porter based on the consumer objects and quality of clothing (this paper, for this discussion). No matter what type of clothing in the design, are covered by a creative design elements, the only difference is the amount of it and the degree of originality.

\subsection{Haute Couture and Creative Design}

In comparison, haute couture are designed by world-renowned designers mostly, of which a considerable part of the works with a strong artistic performance characteristics, originality, plays a leading role in the international fashion trend. Of course, in haute couture, also a small part of it belongs to perfect classic type, and its creativity is not strong.

\subsection{Prét-à-Porter and Creative Design}

For Prét-à-porter, the practicality of its main features, the design often converts the creative concept from haute couture in its own language and location. From this perspective, the originality is not strong. The changes of Prét-à-porter design are mainly reflected in the details of clothing or parts of the key positions, focusing on the functionality of wearing and the improvement of existing, the creativity is mainly reflected in the capture of small taste and the expression of means.

\subsection{Prét-à-Couture and Creative Design}

Somewhere between Haute couture and Prét-à-porter, the originality of Prét-à-couture design is also relatively high, mainly due to that the brands of Prét-à-couture dominant in the world are almost the second-line brands of the famous fashion designers would-wide. The concept of its creative fashion design is almost the same time, as Haute couture from these influential designers or from the excellent designers with a full strength. However, 
Prét-à-couture, after all, is in the overall concept of ready to wear, so, relative to Haute couture, it’s creative design reflects more the restrictions given by objectives with the features of enforceability.

In short, all types of fashion design have the creative qualities and characteristics of creative activity, but their creative designs of clothing have a different degree, and its own performance characteristics in the originality. Exploring further, the main expressions of clothing creative design can be summarized as the subversive type, the innovation type and the functional innovation type.

\section{The Main Expressions and Characteristics of Clothing Creative Design}

\subsection{Subversive Creative Design of Clothing}

Subversive creative design of clothing by definition is that in contrast with the tradition, convention, and mainstream of fashion. It focuses on the leap in the development of clothing and the driving of fashion trends, and it gets innovation in the design philosophy, challenges in the commonplace things, builds up the aesthetic taste of the times seemingly wonderful, touches in the consumer's inner world, leads to revolutionary change, and then increases to the main location replacing the mainstream. The rise of "anti-traditional fashion" in 60's of the 20th century- “mini”, “metal clothes”, “Bikini” (appeared in the 40's, was popular in the 60's) said goodbye to the traditional era when the mature, sophisticated, aristocratic, affectation image of women was considered as beauty. The "Anti-fashion” in late 70's launched by groups of the Japanese designers-unstructured, wrapped, winding fashion, "patch installed", "Beggar look" etc. completely subverted the European fashion style which had always played dominance of the mainstream fashion. The creative fashion design in 80's - "underwear treated as outwear", "gender transition" etc. totally broke the concept of the inherent dress style formatting for a long time. Under the philosophy of environmental protection, the creative fashion design beginning from 90's to the 21st century, —the "minimalism" "deconstruction", "Bohemian", "mix and match style" had been lashing the aesthetic judgments and value judgments of people in the past for fashion violently. Today in the context of "knowledge economy", "information", and "globalization", the fashion creative design with the unprecedented attention is digging out the inherent human desires and demands promoted by the injection of high-tech. The "emotional design", "experience design”, “communication design”, "fast fashion design” and "functional design" have brought the surface form of dress changes, more importantly, the fashion revolution of lifestyle and consumer's behavior. Matt Mattus, who is known as "trend hunter" among American designers, in his book "on the trend of design", pointed out the most famous and creative designers share some common features - they always pursue original design; they always respect true masters; they always impel themselves to approach perfection. He also wrote, the real creation requires far-sighted designers observe and integrate the movement of cultural impact, upon which they build trend beyond popular, and work containing extraordinary cultural values (Mattus, 2009: p. 80).

Subversive fashion design looks absurd, aiming at being totally novel and different, but it is yet not created from vacuum. The fashion-creating designs utilize their unique vision and fulfill their extraordinary talent to erupt of creative thoughts from the soil of time, society, politics, economy, culture, science and technology.

\subsection{Back to the Future Creative Design of Clothing}

While revolutionary thinking is more restricted to elites, most designers create novel fashion design from learning from the past, which makes the fashion trend an inherent flow. This type of fashion design is based upon existing resources and can be further classified into "inter-disciplinary creation" and "innovative creation". The former is regarded as more creative than the latter.

Some scholars express the "inter-disciplinary creation" as the following formulae, "yellow + blue = green". Yet green is composed of yellow and blue, green itself is neither yellow nor blue. The metaphor is utilized very broadly in fashion design. A well-known example is "mix and match". The originality deploys upon new elements generated from the old.

Innovative creation refers to some new design which has structural, functional or formal novelty. The design is upon the skeleton of existing product but yet innovates, which may satisfy the demand of consumers and generates better sale. Although the originality is not high, innovative creation is still essential to the development of fashion, which fits very well with the design of ordinary ready-made clothes (Liu, Wang, \& Gu, 2009). 


\subsection{Creative Functional Design of Clothing}

Creative functional design of clothing focuses on various practical purposes. The current design concentrates on texture, comfort, protectiveness, and health, which is largely dependent on late science and technology. The import of science and technology, especially when merged with new fashion concept, brings revolution for fashion design. For instance, the shark-skin swimsuit promotes motion speed to its extreme which in turn makes streamlined design a trend. The examples are too numerous to mention.

On the other hand, without the utilization of high-tech, the functional innovation itself is already an important pathway for fashion design, though may not be as revolutionary as that with. The multi-function design is a good example. The emergence of "pluggable", "removable", "portable" or "transformable” designs is not a new topic. However, as time and life style change, the design of USB warmer, blanket with sleeves etc. fits very well with "PC Generation". A modern humane design is demand-based. A set of "three-leg" stockings is designed specifically for female consumers and this additional backup very nicely and easily solves the problem of the causal breakage of stockings.

\section{Creative Design of Clothing Is Essential for the Development of Fashion Industry in China}

Since the launching of reform and open-door policy in the 80s of the last century, the fashion industry has be rocketing. At the present, China is the biggest clothes producer and importer. "Made in China" has already spread all over the world. However, the fashion industry of China is still labor-intense, without much creative content and largely dependent on cheap human resource and material, the profit of the style of which is low. We yet haven't had a world-known brand, neither an impact on fashion trend nor value standard. A major reason is China hasn't imported much creativity into fashion design, which of course becomes a central problem to solve. "Even at the beginning of fashion industry development in China, we already emphasized on design, not only on cloth, but every element in Life. At the present moment, it looks that China's design power has been improved, but the cultural impact, generally speaking, the "soft power" is still weak, which requires original creativity of designers and even a harder problem.” (China Sewing Machine Network, 2009)

\subsection{Develop Independent Brands Is an Important Strategy}

Brand is made for its own cultural value and is the carrier of creative design. It tells story and gives content. It is merged with intellectual property and integrates many elements to give new meaning of products. It is a very effective way to bring new, sometimes surprising experience (Mattus, 2009: p. 18).

\subsection{Develop Industry of Creative Fashion Design}

Yuzhou Du, the president of Chinese textile science society, once said, the developmental strategy of the industry ought to focus on prospering creativity, industrializing creative design and promoting creative value standard. It is dependent on the intellect, skill and talent of individuals, with science and technology and protected by law system on intellectual property and finally expressed as high extra-value products and a healthy industry (China Sewing Machine Network, 2009).

\subsection{Foster Experts on Creative Design of Clothing}

Developing fashion creative industry and going the way of creative design, creative talent is the key. They need to have solid professional knowledge and skill, creative mood and ability, and also knowledge in other disciplines which is the source of really original ideas that are not perceived yet by consumers. The fostering of such people is dependent upon supports from whole society, especially professional institutes and schools which are making curriculum in the pipeline. The educational system needs to be up-to-date and the requirement of having brilliant teachers is becoming increasingly high.

\section{Conclusion}

(1) “Creative design" and "technological innovation” are the two principal subjects and the fashion industry development in China. Both need high-degree of creativity. 
(2) Creative fashion design is expressed at product, but may be in various forms.

(3) The styles of creative fashion can be classified as revolutionary, back-to-the-future and functional.

(4) It is essential to have an educational pipeline to foster very able and creative designers.

\section{Acknowledgements}

This research was financially supported by the Shanghai Science and Technology Public Service Platform Project (13DZ2294300); Shanghai Education Research and Innovation Project (13ZS173); Shanghai Educational Science Research Project (B14035); Shanghai Education Commission gifted youth project (ZZGJD12017).

\section{References}

China Sewing Machine Network (2009). Winning, Creative-Du and Ge Bake Dialogue. Source: China Sewing Machine Network, 2009-9-4.

Liu, X. G., Wang, J., \& Gu, W. (2009). Process • Decision-making • Response-Costume Design Methodology (p. 97). Beijing: China Textile Press.

Mattus, M. (Jiao W.-C. translation) (2009). Beyond Trend (p. 80, p. 18). Jinan: Shandong Pictorial Publishing House. 